\title{
Aging results in a decline in cellular energy metabolism in the trophocytes and oenocytes of worker honeybees (Apis mellifera )
}

\author{
Cheng-Yen $\mathrm{Lu}^{1}$, Yu-Lung $\mathrm{CHUANG}^{1}$, Chin-Yuan $\mathrm{Hsu}^{1,2,3}$ \\ ${ }^{1}$ Graduate Institute of Biomedical Sciences, College of Medicine, Chang Gung University, Tao-Yuan, Taiwan \\ ${ }^{2}$ Department of Biomedical Sciences, Chang Gung University, 259, Wen-Hwa 1st Road, Kwei-Shan, Tao-Yuan 333, \\ Taiwan \\ ${ }^{3}$ Department of Obstetrics and Gynecology, Chang Gung Memorial Hospital, Linkou, Taiwan
}

Received 5 January 2017 - Revised 5 May 2017 - Accepted 23 May 2017

\begin{abstract}
Trophocytes and oenocytes of honeybees are used in studies of cellular senescence, but their cellular energy metabolism with age is poorly understood. In this study, the molecules involved in cellular energy metabolism were evaluated in the trophocytes and oenocytes of young and old worker bees. The results revealed that (i) $\beta$-oxidation and protein synthesis decreased with age, (ii) fat and glycogen accumulation increased with age, and (iii) glycolysis did not change with age. These results indicate that the trophocytes and oenocytes of young bees have higher activity of cellular energy metabolism compared with old worker bees and that aging results in a decline in the cellular energy metabolism of worker bees.
\end{abstract}

aging / cellular energy metabolism / trophocyte / oenocyte / honeybee

\section{INTRODUCTION}

Honeybees (Apis mellifera) are a unique model system for aging and longevity studies because queen bees have a much longer lifespan than worker bees and they share the same genome. In addition, they live in large colonies and are easily manipulated, and their genome has been sequenced and is similar to vertebrate genomes (The honeybee genome sequencing consortium 2006; Elsik et al. 2014).

Trophocytes and oenocytes have served as target cells in studies of cellular senescence due to their biological functions as white adipose tissue or liver tissue, ease of isolation from the abdomen, convenient manipulation, and lack of cell division

Corresponding author: C. Hsu, hsu@mail.cgu.edu.tw Handling Editor: Klaus Hartfelder during adulthood (Hsieh and Hsu 2011; Chan et al. 2011; Seehuus et al. 2013). Trophocytes and oenocytes are located in the abdomen and tightly attach to each other to form a single layer of cells around each abdominal segment. Trophocytes are large and irregularly shaped, and oenocytes are small and spherical (Hsieh and Hsu 2011).

The studies of trophocytes and oenocytes in worker bees indicated that young worker bees expressed higher mitochondrial energy utilization, energy-regulated activity, and cellular degradation activity compared with old worker bees and that aging results in a decline in the cellular function of trophocytes and oenocytes (Chuang and Hsu 2013; Hsu and Chan 2013; Hsu and Chuang 2014; Hsu et al. 2014).

To further study the cellular function of trophocytes and oenocytes with age, we evaluate molecules involved in lipid metabolism including $\beta$-hydroxylacyl-CoA dehydrogenase (HOAD), citrate synthase $(\mathrm{CS})$, carnitine palmitoyltransferase 1 
(CPT1), non-esterified fatty acid (NEFA), lipase, fatty acid synthase (FAS), and fat accumulation; in carbohydrate metabolism including phosphofructokinase-2/fructose-2,6-bisphosphatase 3 (PFKFB3), pyruvate kinase (PK), pyruvate dehydrogenase (PDH), lactate, phosphorylated glycogen synthase kinase 3 (p-GSK3), and glycogen; and in protein synthesis including eukaryotic translation initiation factor 4E (eIF4E) and phosphorylated eIF4E binding protein 1 ( $\mathrm{p}-4 \mathrm{EBP} 1)$ in the trophocytes and oenocytes of young and old worker bees to clarify the relationship between cellular energy metabolism and cellular senescence in worker bees.

\section{MATERIALS AND METHODS}

\subsection{Honeybees}

Breeding honeybees (Apis mellifera) was described in our previously studies (Hsu et al. 2014; Hsu and Hsieh 2014). Young (1-day-old) and old (50-day-old) worker bees were selected from the same hive colonies on the same dates for the same experiments.

\subsection{Preparation of supernatants}

The supernatant of trophocytes and oenocytes was obtained as previously described (Hsu and Hsieh 2014). Briefly, trophocytes and oenocytes were isolated from two young or old worker bees, homogenized in phosphate-buffered saline containing protease inhibitors (11697498001; Roche Applied Science; Indianapolis; IN; USA), and centrifuged at $5000 \mathrm{~g}$ for $10 \mathrm{~min}$ at $4{ }^{\circ} \mathrm{C}$. The resulting supernatant was collected and assayed immediately. The protein concentration was determined using a protein assay reagent (500-0006; Bio-Rad Laboratories, Hercules, CA, USA) by monitoring the wavelength of $595 \mathrm{~nm}$ at room temperature. Ten replicates were performed, and 20 young and old worker bees in total were used.

\subsection{3-Hydroxyacyl-CoA dehydrogenase activity assay}

HOAD activity was assayed as previously described with minor modification (Hsu and Chan 2013). Briefly, $10 \mu \mathrm{L}$ of supernatant (described in
Section 2.2) or potassium phosphate buffer (used as a control) was mixed with $280 \mu \mathrm{L}$ of $100 \mathrm{mM}$ potassium phosphate buffer $(\mathrm{pH} 7.3), 5 \mu \mathrm{L}$ of $6.4 \mathrm{mM}$ nicotinamide adenine dinucleotide, reduced form (NADH), and $5 \mu \mathrm{L}$ of $5.4 \mathrm{mM}$ acetoacetyl-coenzyme A (CoA) in 96-well plate. Enzymatic activity was measured as the oxidation of NADH at $340 \mathrm{~nm}$ and $37^{\circ} \mathrm{C}$ using a UV/VIS spectrophotometer (SpectraMax M2, Molecular Devices, NY, USA) and is expressed as nmol min ${ }^{-1} \mathrm{mg}^{-1}$ of protein. Ten replicates were performed, and 20 young and old worker bees in total were used.

\subsection{Citrate synthase activity assay}

CS activity assays were performed as previously described with minor modification (Hsu and Chan 2013). Briefly, $8 \mu \mathrm{L}$ of supernatant (described in Section 2.2) or assay solution (used as a control) was mixed with $178 \mu \mathrm{L}$ of assay solution, $2 \mu \mathrm{L}$ of $30 \mathrm{mM}$ acetyl CoA, and $2 \mu \mathrm{L}$ of $10 \mathrm{mM}$ 5,5'-dithio-bis-(2-nitrobenzoic acid) (DTNB), and $10 \mu \mathrm{L}$ of $10 \mathrm{mM}$ oxaloacetic acid solution in 96-well plate. Enzyme activity was measured at $412 \mathrm{~nm}$ and $37{ }^{\circ} \mathrm{C}$ using a UV/VIS spectrophotometer (SpectraMax M2, Molecular Devices) and is expressed as nmol min ${ }^{-1} \mathrm{mg}^{-1}$ of protein. Ten replicates were performed, and 20 young and old worker bees in total were used.

\subsection{Carnitine palmitoyltransferase 1 activity assay}

Carnitine palmitoyltransferase 1 (CPT1) activity was assayed as previously described with minor modification (Karlic et al. 2002). Briefly, $10 \mu \mathrm{L}$ of supernatant (described in Section 2.2) or Tris-HCl-DTNB buffer (used as a control) was mixed with $187 \mu \mathrm{L}$ of Tris-HCl-DTNB buffer (116 mM Tris, $2.5 \mathrm{mM}$ EDTA, $2 \mathrm{mM}$ DTNB, and $0.2 \%$ Triton $\mathrm{X}-100, \mathrm{pH} 8.0)$ and $1 \mu \mathrm{L}$ of $10 \mathrm{mM}$ palmitoyl-CoA and incubated for $5 \mathrm{~min}$ at room temperature. The reaction was initiated by the addition of $2 \mu \mathrm{L}$ of $1.2 \mathrm{mM}$ L-carnitine solution. Enzymatic activity was measured at $412 \mathrm{~nm}$ for $120 \mathrm{~s}$ in 10 -s intervals at $37{ }^{\circ} \mathrm{C}$ using a UV/ VIS spectrophotometer (SpectraMax M2, Molecular Devices) and is expressed as nmol $\mathrm{min}^{-1} \mathrm{mg}^{-1}$ 
of protein. Ten replicates were performed, and 20 young and old worker bees in total were used.

\subsection{Non-esterified fatty acid concentration assay}

The NEFA concentrations were quantified using a NEFA kit (FA115, Randox Laboratories, Antrim, UK). Briefly, 3.3 $\mu \mathrm{L}$ of supernatant (described in Section 2.2) was mixed with $66 \mu \mathrm{L}$ of enzyme/coenzyme mixed reagent in a 96-well microplate and incubated at $37{ }^{\circ} \mathrm{C}$ for $10 \mathrm{~min}$. Subsequently, $132 \mu \mathrm{L}$ of maleimide/enzyme mixed reagent was added, and the plate was incubated at $37^{\circ} \mathrm{C}$ for $10 \mathrm{~min}$. Protein concentrations were determined using a protein assay reagent (500-0006, Bio-Rad Laboratories). NEFA concentrations were measured at $550 \mathrm{~nm}$ and $37^{\circ} \mathrm{C}$ using a UV/VIS spectrophotometer (SpectraMax M2, Molecular Devices) and standardized to the background and are expressed as $\mu \mathrm{mol} \mathrm{mg}^{-1}$ of protein. Ten replicates were performed, and 20 young and old worker bees in total were used.

\subsection{Lipase activity assay}

Lipase activity was assayed using a lipoprotein lipase activity assay kit (STA-610, Cell Biolabs, CA, USA). After recording the background luminescence, $100 \mu \mathrm{L}$ of a diluted lipase standard solution $(0,3.9,7.8,15.6,31.2,62.5$, and $125 \mathrm{mUnits} / \mathrm{mL}$ ) or $100 \mu \mathrm{L}$ of supernatant (described in Section 2.2) was mixed with $100 \mu \mathrm{L}$ of a diluted lipase fluorometric substrate in a 96-well microplate and incubated for $30 \mathrm{~min}$ at $37^{\circ} \mathrm{C}$ in the dark. Then, $20 \mu \mathrm{L}$ of stop solution was added, followed by incubation for an additional $15 \mathrm{~min}$ in the dark. Fluorescence was monitored at an excitation wavelength of 480-485 nm and an emission wavelength of 515-525 nm using a UV/VIS spectrophotometer (SpectraMax M2, Molecular Devices). Protein concentrations were determined using a protein assay reagent (5000006, Bio-Rad Laboratories). Lipase activity is expressed as Unit $\mathrm{mg}^{-1}$ protein. A calibration curve using lipase standards was used to quantify lipase activity. Ten replicates were performed, and 20 young and old worker bees in total were used.

\subsection{Fatty acid synthase activity assay}

Fatty acid synthase (FAS) activity was assayed as previously described (Nepokroeff et al. 1975). Briefly, 33.3 $\mu \mathrm{L}$ of supernatant (described in Section 2.2) was mixed with $163.3 \mu \mathrm{L}$ of $2.0 \mathrm{M}$ potassium phosphate buffer, $\mathrm{pH} 7.1,16.7 \mu \mathrm{L}$ of $20 \mathrm{mM}$ dithiothreitol, $20 \mu \mathrm{L}$ of $0.25 \mathrm{mM}$ acetyl$\mathrm{CoA}, 16.7 \mu \mathrm{L}$ of $60 \mathrm{mM}$ EDTA, and $33.3 \mu \mathrm{L}$ of $0.39 \mathrm{mM}$ malonyl-CoA in a $96-$-well microplate. Subsequently, $16.7 \mu \mathrm{L}$ of $6 \mathrm{mM}$ nicotinamide adenine dinucleotide phosphate (NADPH) was added to the mixture. Enzymatic activity was measured as the oxidation of NADPH at $340 \mathrm{~nm}$ and $37{ }^{\circ} \mathrm{C}$ using a UV/VIS spectrophotometer (SpectraMax M2, Molecular Devices) and is expressed as nmol oxidized NADPH $\mathrm{min}^{-1} \mathrm{mg}^{-1}$ of protein. Protein concentrations were determined using a protein assay reagent (500-0006, Bio-Rad Laboratories). Ten replicates were performed, and 20 young and old worker bees in total were used.

\subsection{Fat accumulation assay}

Fat accumulation was determined by transmission electron microscopy (TEM) (Chuang and Hsu 2013). Briefly, trophocytes from one young and one old worker bee were fixed in $2.5 \%$ glutaraldehyde, postfixed in $1 \%$ osmium tetroxide, dehydrated, and embedded in Spurr's resin. Thin sections (60-90 $\mathrm{nm}$ in thickness) were cut, stained, and examined using a TEM system (JEOL JEM-2000EXII; Tokyo, Japan). Fat accumulation was evaluated according to the oil area/ oil vesicle area ratio. The oil area and oil vesicle area were analyzed using Photoshop (CS6). Five replicates were performed, and five young and old worker bees in total were used. Twenty oil vesicles in each young and old worker bee were used to evaluate oil accumulation. Thus, the results for fat accumulation were derived from 100 oil vesicles.

\subsection{Pyruvate kinase activity assay}

Pyruvate kinase (PK) activity was assayed using a PK activity assay kit (K709-100, BioVision, CA, USA). After recording the 
background luminescence, $50 \mu \mathrm{L}$ of a diluted pyruvate standard solution $(0,2,4,6,8$, and $10 \mathrm{nmol} / \mathrm{well}$ ) or $50 \mu \mathrm{L}$ of supernatant (described in Section 2.2) was mixed with $50 \mu \mathrm{L}$ of reaction mix in a 96-well microplate, and photometric measurements were immediately performed (SpectraMax M2, Molecular Devices) at $570 \mathrm{~nm}$ for $20 \mathrm{~min}$ in 5 -min intervals at $25^{\circ} \mathrm{C}$. Protein concentrations were determined using a protein assay reagent (500-0006, Bio-Rad Laboratories). A calibration curve using PK standards was used to quantify PK activity. PK activity is expressed as mUnit $\mathrm{mg}^{-1}$ of protein. Ten replicates were performed, and 20 young and old worker bees in total were used.

\subsection{Pyruvate dehydrogenase activity assay}

PDH activity was assayed as previously described (Brown and Perham 1976). Briefly, $5 \mu \mathrm{L}$ of supernatant (described in Section 2.2) was mixed with $150 \mathrm{mM}$ MOPS-HCl buffer, $\mathrm{pH} 7.4$, $12 \mathrm{mM} \mathrm{MgCl}_{2}, 0.6 \mathrm{mM} \mathrm{CaCl}_{2}, 18 \mathrm{mM}$ thiamine pyrophosphate, $0.72 \mathrm{mM} \mathrm{CoA}, 20 \mathrm{mM}$ nicotinamide adenine dinucleotide, oxidized form $\left(\mathrm{NAD}^{+}\right), 15.6 \mathrm{mM}$ cysteine solution, $\mathrm{pH} 7.4$, and $75 \mathrm{mM}$ pyruvate. Enzymatic activity was measured as the production of NADH at $340 \mathrm{~nm}$ and $37{ }^{\circ} \mathrm{C}$ using a UV/VIS spectrophotometer (SpectraMax M2, Molecular Devices) and is expressed as nmol min ${ }^{-1} \mathrm{mg}^{-1}$ of protein. Protein concentrations were determined using a protein assay reagent (500-0006, Bio-Rad Laboratories). Ten replicates were performed, and 20 young and old worker bees in total were used.

\subsection{Lactate concentration assay}

Lactate concentrations were quantified using a Lactate Colorimetric/Fluorometric Assay Kit (K607-100, BioVision). Briefly, trophocytes and oenocytes from two young and two old worker bees were homogenized in $100-\mu \mathrm{L}$ lactate assay buffer using a polytron and sonicator and centrifuged at $5000 \mathrm{~g}$ for $10 \mathrm{~min}$ to obtain supernatants. Protein concentrations were determined using a commercial protein assay reagent $(500-0006$, BioRad Laboratories). After recording the background luminescence, $50 \mu \mathrm{L}$ of a diluted lactate standard solution $(0,2,4,6$, and $8 \mathrm{nmol})$ or $50 \mu \mathrm{L}$ of the supernatant was added to a solution containing $46-\mu \mathrm{L}$ lactate assay buffer, $2 \mu \mathrm{L}$ lactate enzyme mix, and $2 \mu \mathrm{L}$ probe for $30 \mathrm{~min}$. Then, spectrophotometric measurements were performed at $570 \mathrm{~nm}$ at room temperature. A calibration curve using lactate standards was used to quantify lactate concentrations. Lactate concentrations are expressed as nmol mg ${ }^{-1}$ of protein. Ten replicates were performed, and 20 young and old worker bees in total were used.

\subsection{Glycogen accumulation and glycogen concentration assays}

Glycogen accumulation was determined by periodic acid Schiff staining as previously described (Valentine and Cooper 2006). Briefly, trophocytes and oenocytes from one young and one old worker bee were stained with $1 \%$ periodic acid solution (395; Sigma, Saint Louis, Missouri, USA) for $5 \mathrm{~min}$ and then with Schiff's reagent for $15 \mathrm{~min}$. Next, the cells were counterstained with hematoxylin for $90 \mathrm{~s}$. Finally, they were observed under a light microscope (Olympus BX61, Tokyo, Japan). The areas of glycogen granules were determined using ImageJ software (NIH, Bethesda, MA, USA). Ten replicates were performed, and ten young and old worker bees in total were used.

Glycogen concentrations were measured using a glycogen assay kit (K646-100, BioVision). Briefly, $10 \mathrm{mg}$ of trophocytes and oenocytes from one young and one old worker bee was homogenized with $200 \mu \mathrm{L}$ of $\mathrm{ddH}_{2} \mathrm{O}$. The homogenates were boiled and centrifuged at $18,000 \mathrm{~g}$ to obtain supernatants, which were used directly in the assay. After recording the background luminescence, $50 \mu \mathrm{L}$ of a diluted glycogen standard solution $(0,0.008,0.016,0.024,0.032$, and $0.04 \mu \mathrm{g} /$ $\mu \mathrm{L}$ ) or $50 \mu \mathrm{L}$ of supernatant was mixed with $2 \mu \mathrm{L}$ of hydrolysis enzyme mix and $50 \mu \mathrm{L}$ of reaction mix. Spectrophotometric measurements were performed at $570 \mathrm{~nm}$ at room temperature using an ELISA plate reader (Synergy HT, BioTek, VT, USA). A calibration curve using glycogen standards was used to quantify glycogen concentrations. The glycogen concentrations are expressed 
as $\mu \mathrm{g} \mu \mathrm{L}^{-1}$. Ten replicates were performed, and ten young and old worker bees in total were used.

\subsection{Western blot assay}

Western blotting was performed as previously described (Hsu and Chuang 2014). Briefly, proteins $(30 \mu \mathrm{g})$ from the supernatants were run on $10-15 \%$ acrylamide SDS-PAGE gels and transferred to polyvinylidene fluoride membranes. Then, the membranes were blocked for $1 \mathrm{~h}$ at $25^{\circ} \mathrm{C}$ and subsequently incubated with antibodies against phosphofructokinase-2/fructose-2,6bisphosphatase 3 (PFKFB3) (1:1000; GTX122577, GeneTex, CA, USA), phosphorylated glycogen synthase kinase 3 (p-GSK3) (1:1000; 9331, Cell Signaling, MA, USA), eukaryotic translation initiation factor 4E (eIF4E) (1:1000; 9742, Cell Signaling), or phosphorylated eIF4E binding protein 1 (p-4EBP1) (1:1000; GTX50259, GeneTex). Next, the membranes were probed with the respective secondary antibody labeled with horseradish peroxidase $(1: 10,000)$. Immunolabeled proteins were detected using chemiluminescence (PerkinElmer, Covina, CA, USA), analyzed with ImageJ software (NIH, Bethesda), and normalized to tubulin. Ten replicates were performed, and 20 young and old worker bees in total were used.

\subsection{Statistical analysis}

Differences in the mean values between the two age groups of bees were examined using two-sample $t$ tests. A $P$ value of less than 0.05 was considered significant.

\section{RESULTS}

\section{1. $\beta$-oxidation}

To determine the relationship between lipid metabolism and aging, we assayed the activities of HOAD, CS, and CPT1 in the trophocytes and oenocytes of young and old worker bees. The mean HOAD activities were 5.21 \pm 1.19 and $3.62 \pm 0.70 \mathrm{nmol} \mathrm{min}{ }^{-1} \mathrm{mg}^{-1}$ of protein in the trophocytes and oenocytes of young and old worker bees, indicating no significant difference in activity ( $n=10, P>0.05$; Figure 1a). The mean CS activities were $0.15 \pm 0.01$ and $0.27 \pm 0.05 \mu \mathrm{mol} \mathrm{min}{ }^{-1} \mathrm{mg}^{-1}$ of protein in the trophocytes and oenocytes of young and old worker bees, indicating increased activity in old worker bees $(n=10, P<0.01$; Figure $1 b)$. The mean CPT1 activities were $15.35 \pm 0.47$ and $12.85 \pm 0.77 \mathrm{nmol} \mathrm{min}{ }^{-1} \mathrm{mg}^{-1}$ of protein in the trophocytes and oenocytes of young and old worker bees, indicating increased activity in young worker bees $(n=10, P<0.05$; Figure $1 c)$. The HOAD activity/CS activity (HOAD/CS) and CPT1 activity/CS activity (CPT1/CS) ratios indicate the relative importance of $\beta$-oxidation compared to aerobic metabolism (Cordiner and Egginton 1997; Desrosiers et al. 2008). The $\mathrm{HOAD} / \mathrm{CS}$ ratios indicated that young worker bees had increased $\beta$-oxidation compared with old worker bees $(n=10, P<0.05$; Figure $1 \mathrm{~d})$, and similar results were observed for the CPT1/ CS ratios $(n=10, P<0.01$; Figure $1 \mathrm{e})$.

\subsection{NEFA concentration, lipase activity, FAS activity, and fat accumulation}

Further, we analyzed NEFA concentrations, lipase activity, FAS activity, and fat accumulation in the trophocytes and oenocytes of young and old worker bees. The mean NEFA concentrations were $0.20 \pm 0.01$ and $0.17 \pm 0.01 \mu \mathrm{mol} \mathrm{mg}^{-1}$ of protein in the trophocytes and oenocytes of young and old worker bees, indicating increased concentration in young worker bees $(n=10, P<0.01$; Figure 2a). The mean lipase activities were

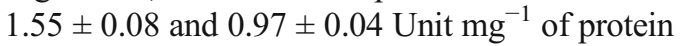
in the trophocytes and oenocytes of young and old worker bees, demonstrating increased activity in young worker bees ( $n=10, P<0.05$; Figure $2 b)$. The mean FAS activities were $0.57 \pm 0.12$ and $1.44 \pm 0.27 \mathrm{NADPH}$ nmol min $\mathrm{mg}^{-1}$ of protein in the trophocytes and oenocytes of young and old worker bees, indicating increased activity in old worker bees $(n=10, P<0.05$; Figure $2 \mathrm{c})$. Fat accumulation in trophocytes was significantly decreased in young worker bees compared with old worker bees (Figure 2d), with mean oil area/oil vesicle area ratios of $44.71 \pm 2.11$ and $90.31 \pm 1.46 \%(n=100, P<0.01$; Figure $2 \mathrm{e})$. 
a
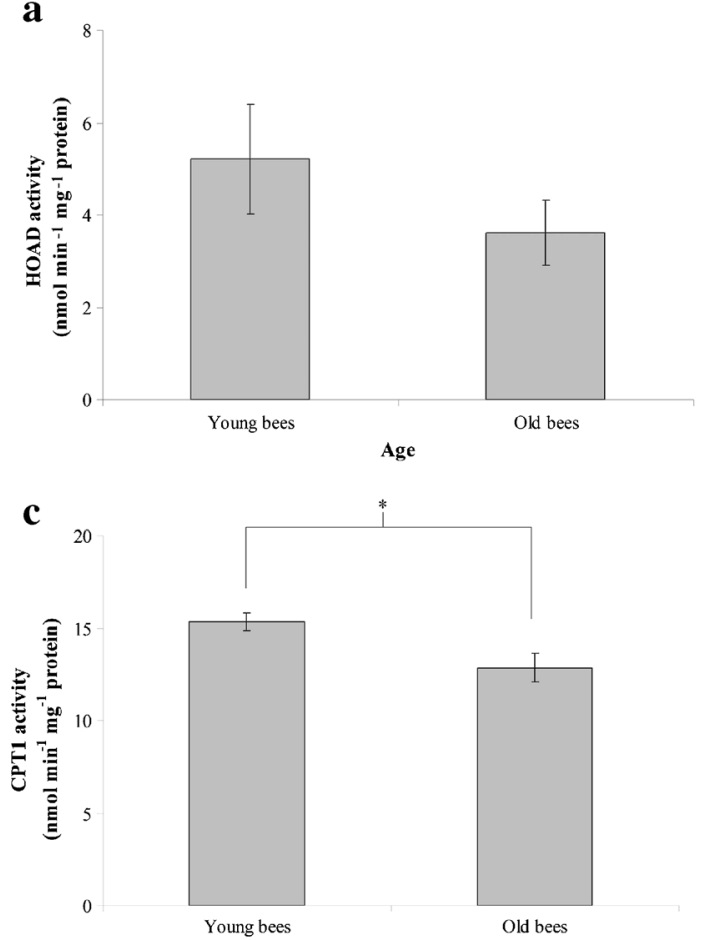

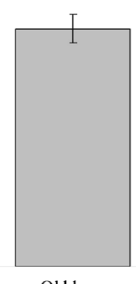

Old bees b

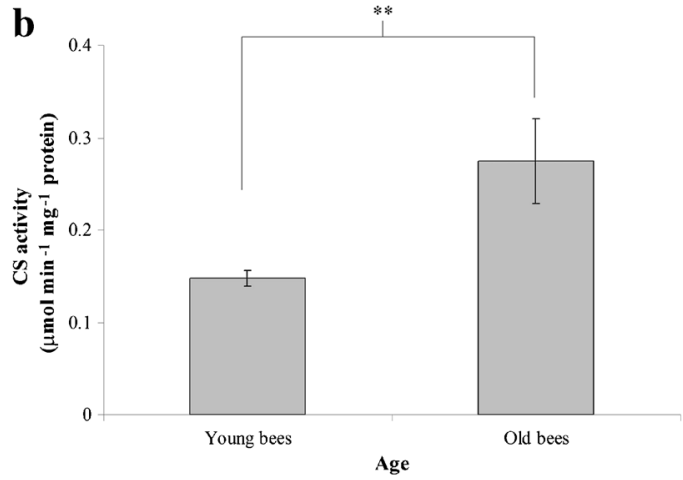

d

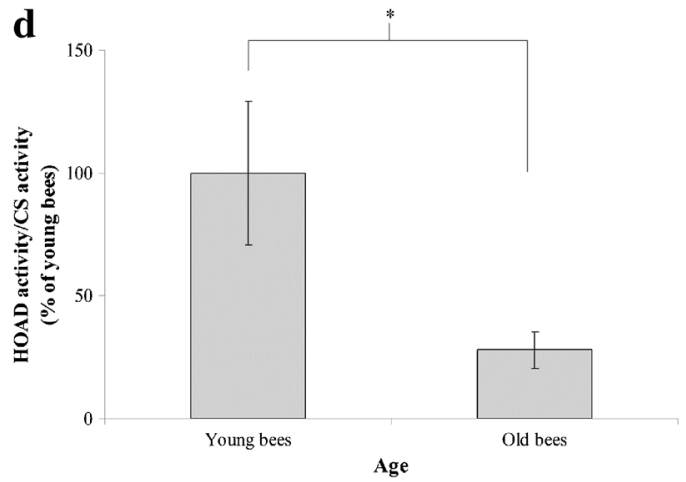

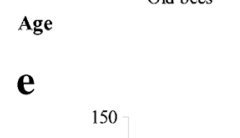
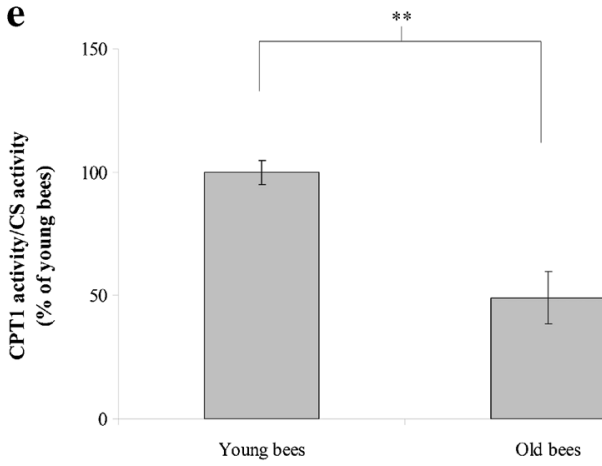

Figure 1. HOAD, CS, and CPT1 activities and HOAD/CS and CPT1/CS ratios in the trophocytes and oenocytes of young and old worker bees. HOAD (a), CS (b), and CPT1 (c) activities are presented as the mean \pm standard error of the mean $(\mathrm{SEM})(n=10)$. The HOAD/CS $(\mathbf{d})$ and CPT1/CS (e) ratios were normalized to the ratios in young worker bees; the results are shown as percentages and represent the mean $\pm \operatorname{SEM}(n=10)$. The asterisks indicate significant differences $(* P<0.05, * * P<0.01$; two-sample $t$ test $)$.

\subsection{Glycolysis and lactate concentration}

To determine the relationship between carbohydrate metabolism and aging, we examined PFKFB3 expression, PK activity, PDH activity, and lactate concentrations in the trophocytes and oenocytes of young and old worker bees.
PFKFB3 expression in the trophocytes and oenocytes of young and old worker bees was not a significant difference $(n=10, P>0.05$; Figure $3 \mathrm{a}, \mathrm{b})$. The mean PK activities were

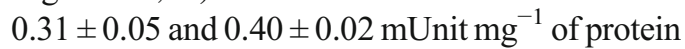
in the trophocytes and oenocytes of young and old worker bees, indicating no significant difference 

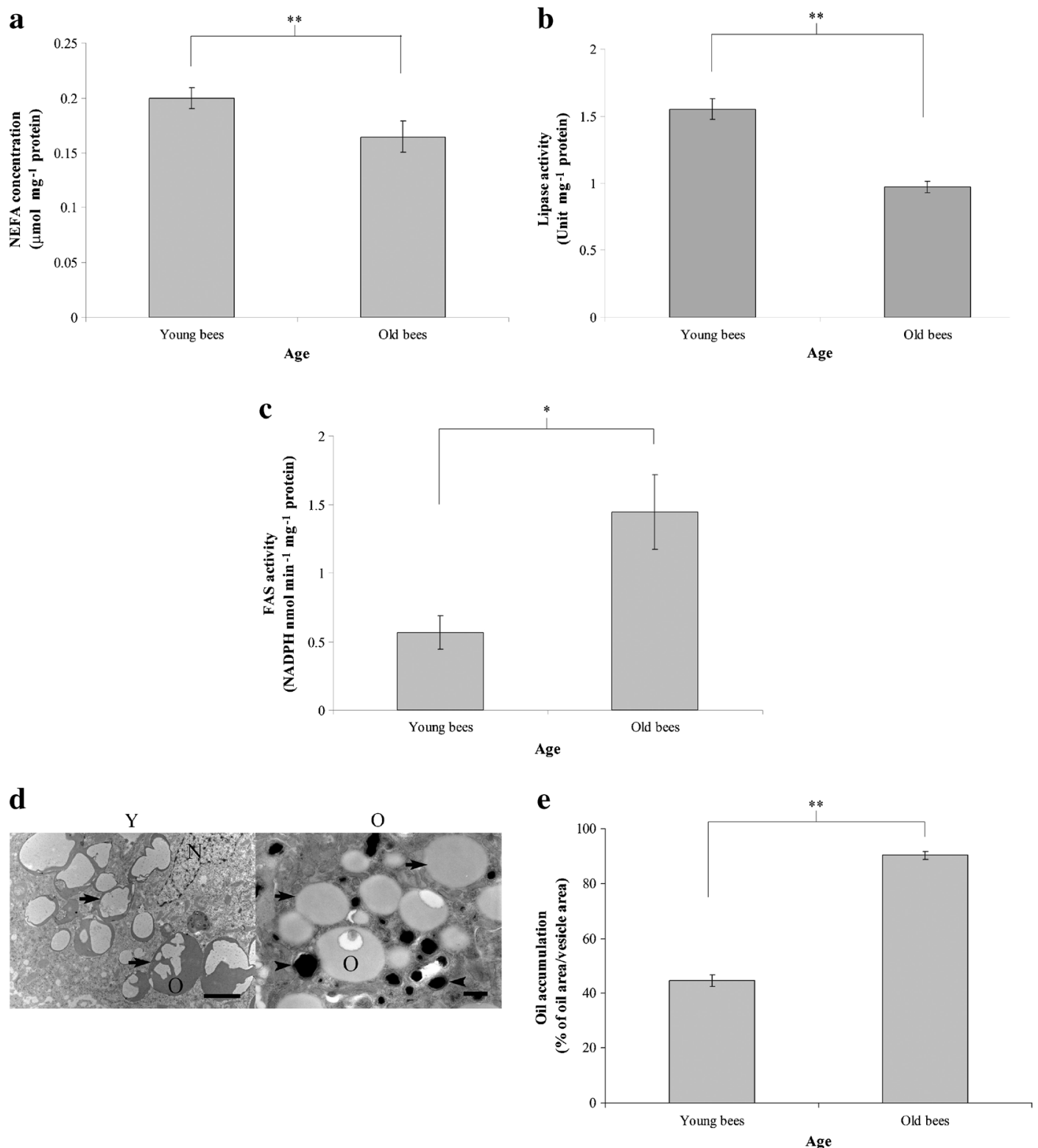

Figure 2. NEFA concentrations, lipase activity, FAS activity, and fat accumulation in the trophocytes and oenocytes of young and old worker bees. a NEFA concentrations are presented as the mean \pm SEM $(n=10)$. b Lipase activities are presented as the mean $\pm \operatorname{SEM}(n=10)$. c FAS activities are presented as the mean $\pm \operatorname{SEM}(n=10)$. d Fat accumulation in the oil vesicles of trophocytes was assessed by TEM. $Y$ young worker bees, $O$ old worker bees, $N$ nucleus, arrow oil vesicle, arrowhead iron granule. Scale bar $2 \mu \mathrm{m}$ in young worker bees and $0.5 \mu \mathrm{m}$ in old worker bees. e Fat accumulation results are presented as the mean $\pm \operatorname{SEM}(n=100)$. The asterisks indicate significant differences $(* P<0.05, * * P<0.01$; two-sample $t$ test).

in activity ( $n=10, P>0.05$; Figure $3 \mathrm{c})$. The mean PDH activities were $2.71 \pm 0.72$ and $3.56 \pm 0.84 \mathrm{nmol} \mathrm{min}^{-1} \mathrm{mg}^{-1}$ of protein in the trophocytes and oenocytes of young and old worker bees, indicating no significant difference in activity ( $n=10, P>0.05$; Figure $3 \mathrm{~d})$. The 
$\mathbf{a}$

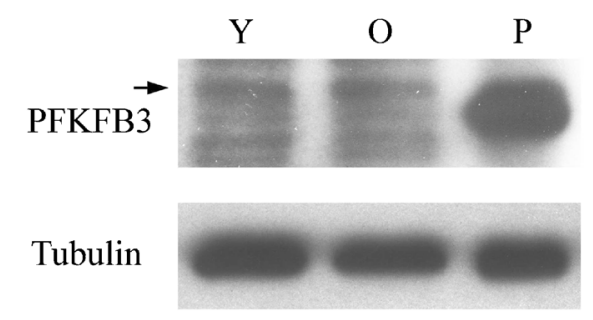

c

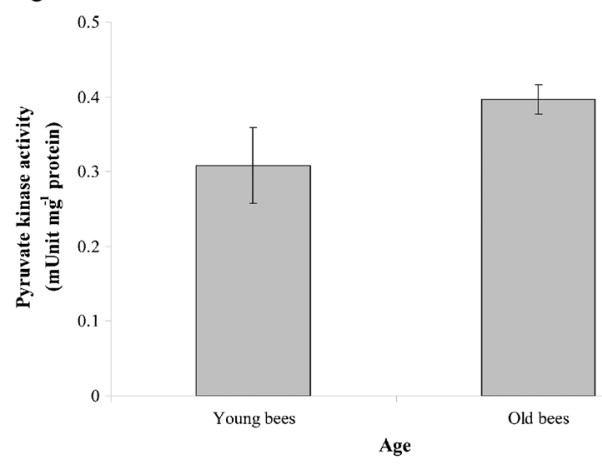

e

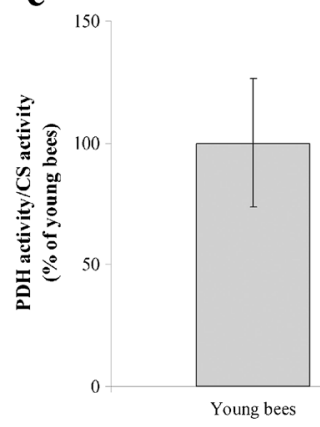

b

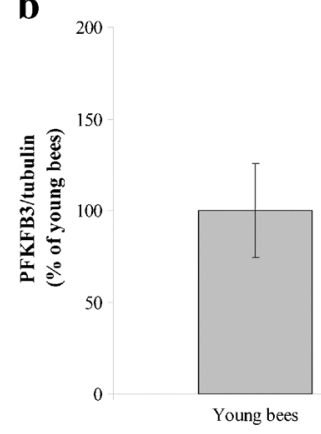

d

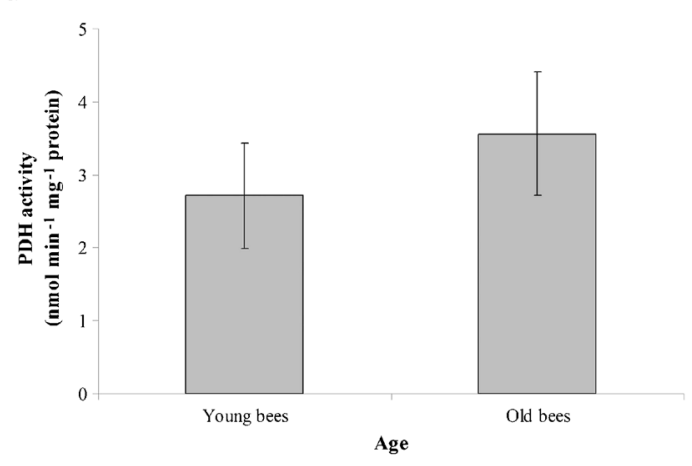

$\mathbf{f}$

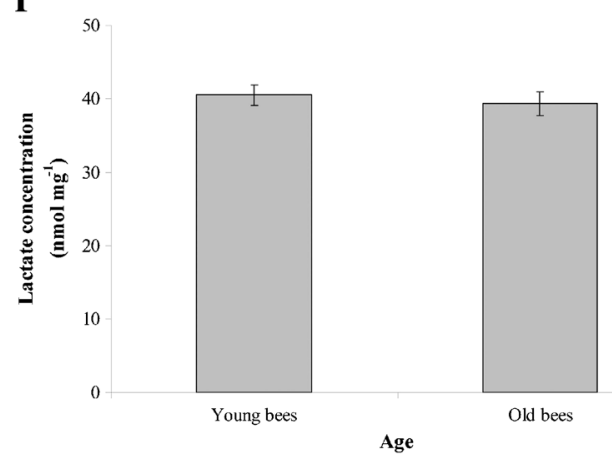

Figure 3. PFKFB3 expression, $\mathrm{PK}$ activity, $\mathrm{PDH}$ activity, the $\mathrm{PDH} / \mathrm{CS}$ ratio, and lactate concentrations in the trophocytes and oenocytes of young and old worker bees. a PFKFB3 expression was analyzed by Western blotting. Tubulin served as a loading control. $Y$ young worker bees, $O$ old worker bees, $P$ positive control (HeLa cells). b PFKFB3 was normalized to the expression in young worker bees; the results are shown as percentages and represent the mean $\pm \operatorname{SEM}(n=20)$. c PK activities are presented as the mean $\pm \operatorname{SEM}(n=10)$. d PDH activities are presented as the mean $\pm \operatorname{SEM}(n=10)$. e The PDH/CS ratio was normalized to the ratio in young worker bees; the results are shown as percentages and represent the mean $\pm \operatorname{SEM}(n=10)$. f Lactate concentrations are presented as the mean $\pm \operatorname{SEM}(n=10)$. The asterisks indicate significant differences $(* P<0.05, * * P<0.01$; two-sample $t$ test).

$\mathrm{PDH}$ activity/CS activity $(\mathrm{PDH} / \mathrm{CS})$ ratio is a measure of the relative importance of glycolysis compared to aerobic metabolism. The $\mathrm{PDH} / \mathrm{CS}$ ratios were $0.019 \pm 0.005$ and $0.015 \pm 0.005$ in the trophocytes and oenocytes of young and old worker bees, indicating no significant difference in glycolysis ( $n=10, P>0.05$; Figure $3 \mathrm{e}$ ). The lactate concentrations were used to evaluate 
anaerobic metabolism. The mean lactate concentrations were $40.51 \pm 1.40$ and $39.34 \pm 1.65 \mathrm{nmol} \mathrm{mg}^{-1}$ of protein in the trophocytes and oenocytes of young and old worker bees, indicating no significant difference in anaerobic metabolism $(n=10, P>0.05$; Figure 3f).

\section{4. p-GSK3 level, glycogen content, and glycogen accumulation}

Furthermore, we evaluated glycogen synthesis and accumulation via assaying p-GSK3 levels and glycogen content in the trophocytes and oenocytes of young and old worker bees. The trophocytes and oenocytes of young worker bees had a significantly higher $\mathrm{p}-\mathrm{GSK} 3$ level compared with old worker bees $(n=10, P<0.05$; Figure 4a, b), indicating increased glycogen synthase activity in young worker bees. The trophocytes and oenocytes of young worker bees had significantly decreased glycogen accumulation compared with old worker bees ( $n=10, P<0.01$; Figure $4 \mathrm{c}, \mathrm{d})$, and similar results were observed for glycogen content in the trophocytes and oenocytes of young and old worker bees, with $0.11 \pm 0.01$ and $0.26 \pm 0.06 \mu \mathrm{g} \mu \mathrm{L}^{-1}$, respectively $(n=10$, $P>0.05$; Figure $4 \mathrm{e})$.

\subsection{Protein synthesis}

To determine the relationship between protein synthesis and aging, we analyzed eIF4E and p4EBP1 levels in the trophocytes and oenocytes of young and old worker bees. The trophocytes and oenocytes of young worker bees had significantly increased eIF4E expression compared with old worker bees ( $n=10, P<0.05$; Figure $5 \mathrm{a}, \mathrm{b}$ ). Similar results were observed for the p-4EBP1 level in the trophocytes and oenocytes of young and old worker bees $(n=10, P<0.05$; Figure $5 \mathrm{c}$, d), indicating increased protein synthesis in young worker bees.

\section{DISCUSSION}

In this study, we evaluated molecules involved in cellular energy metabolism in the trophocytes and oenocytes of young and old worker bees. The findings indicated that the trophocytes and oenocytes of young worker bees had higher activity of cellular energy metabolism compared with old worker bees and that aging resulted in decreased cellular energy metabolism in the trophocytes and oenocytes of worker bees.

\section{1. $\beta$-oxidation, NEFA concentrations, and lipase activity}

The HOAD/CS and CPT1/CS ratios in trophocytes and oenocytes were reduced with age, representing that $\beta$-oxidation was reduced with age in worker bees. These results are in agreement with previous studies indicating that children have increased fat oxidation compared with adults (Kostyak et al. 2007) and elderly adults (Levadoux et al. 2001), that $\beta$-oxidation decreases with age in rat liver (Son et al. 2012), rat muscles (Tucker and Turcotte 2002), and human female muscles (Calles-Escandon et al. 1995), and that the expression of genes and levels of metabolites involved in fatty acid oxidation decrease with age in mice (Houtkooper et al. 2011).

NEFAs are hydrolyzed from triglycerides by lipase and undergo $\beta$-oxidation. NEFAs are converted to acyl-CoA and then acetyl-CoA. AcetylCoA enters tricarboxylic acid cycle to generate $\mathrm{NADH}$ and $\mathrm{H}^{+}$for ATP synthesis and increase mitochondrial membrane potential $(\Delta \psi \mathrm{m})$ and reactive oxygen species (ROS) production (Nicholls 2004). In this study, lipase activity decreased with age in bees, which is consistent with previous studies of rats (Carlile and Lacko 1985; Bey et al. 2001). NEFA concentrations measured are consistent with lipase activities determined. Parallel decreases in NEFA concentration, lipase activity, and $\beta$-oxidation with age suggest that young worker bees have high lipase activity for generation of a large amount of NEFAs for $\beta$ oxidation. The increased $\beta$-oxidation in young worker bees is indicative of a high level of cellular energy. This inference is supported by previous studies demonstrating that young worker bees have high $\mathrm{NAD}^{+}$concentrations (Chuang and Hsu 2013), $\Delta \psi \mathrm{m}$ (Chuang and Hsu 2013), ATP concentrations (Chuang and Hsu 2013; Hsu and Chan 2013; Hsu and Chuang 2014), ROS levels 
$\mathbf{a}$

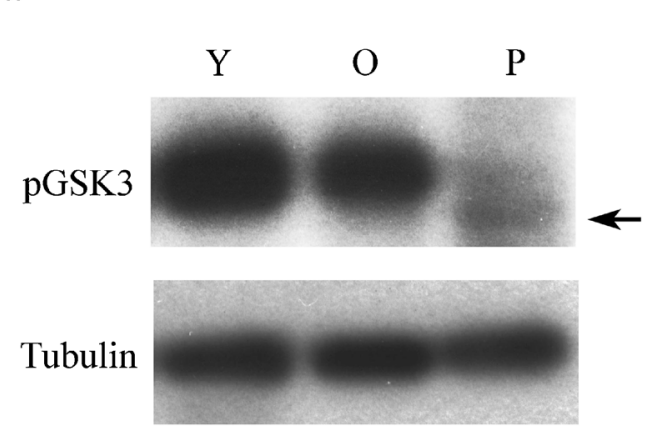

c

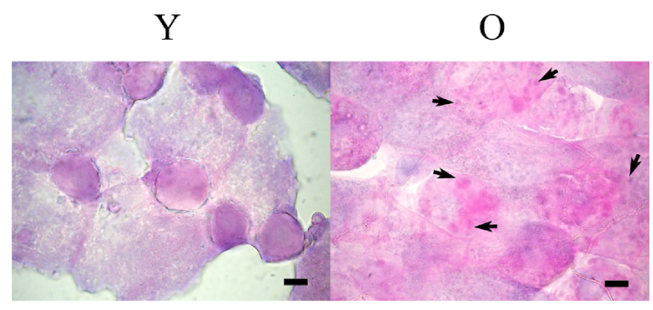

b

150

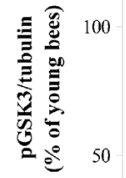

d

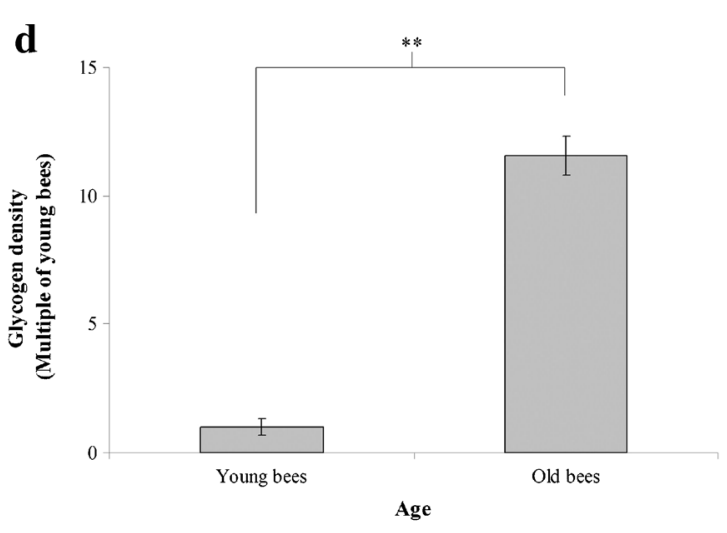

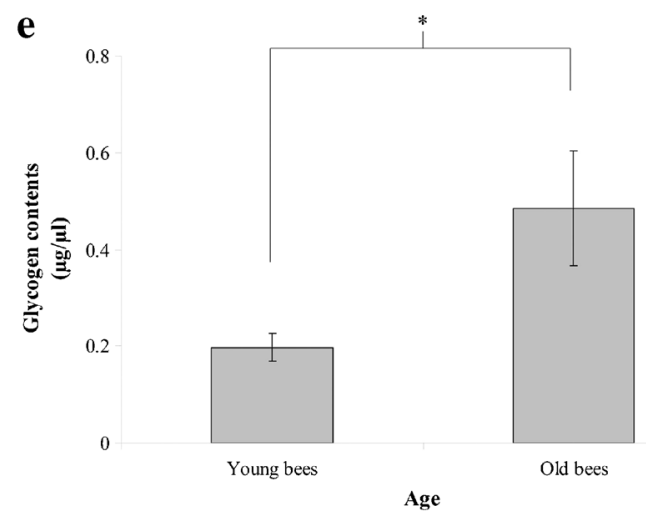

Figure 4. p-GSK3 levels, glycogen accumulation, and glycogen concentrations in the trophocytes and oenocytes of young and old worker bees. a p-GSK3 was analyzed by Western blotting. Tubulin served as a loading control. $Y$ young worker bees, $O$ old worker bees, $P$ positive control (arrow, rat liver). b p-GSK3 was normalized to the level in young worker bees; the results are shown as percentages and represent the mean $\pm \operatorname{SEM}(n=10)$. $\mathbf{c}$ Glycogen accumulation was examined by light microscopy. The arrows indicate glycogen. $Y$ young worker bees, $O$ old worker bees. Scale bar $20 \mu \mathrm{m}$. d Glycogen accumulation was normalized to the level in young worker bees; the results are presented as fold differences and represent the mean $\pm \operatorname{SEM}(n=10)$. e Glycogen concentrations are presented as the mean $\pm \operatorname{SEM}(n=10)$. The asterisks indicate significant differences $\left(* P<0.05,{ }^{* *} P<0.01\right.$; twosample $t$ test).

(Hsu and Hsieh 2014), and superoxidase dismutase (SOD) activity (Hsu and Hsieh 2014).
Integrating the finding of this and previous studies, we propose that $\mathrm{NADH}$ and $\mathrm{H}^{+}$produced by 
$\mathbf{a}$

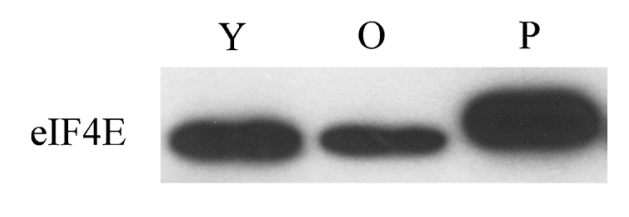

Tubulin

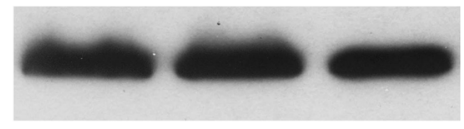

c

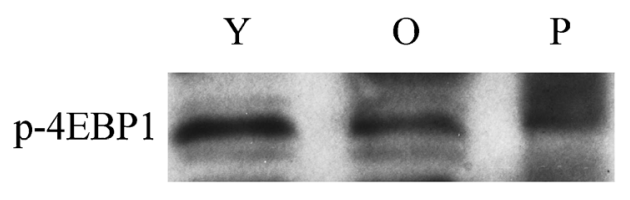

Tubulin

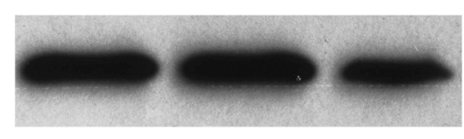

b

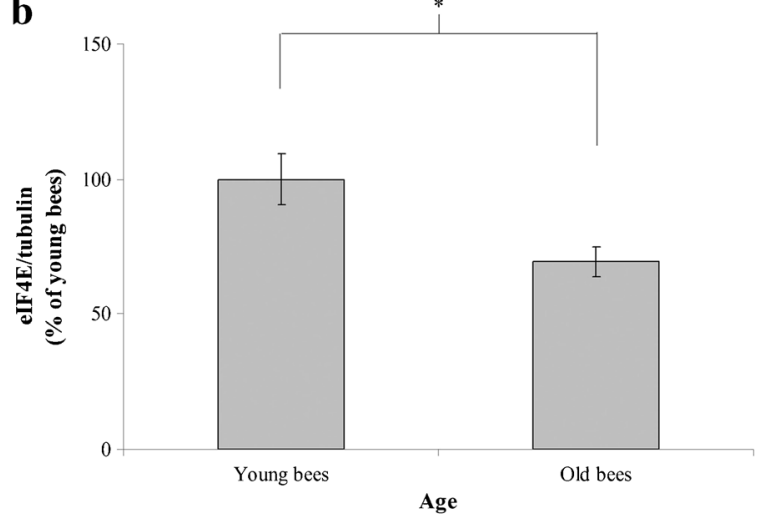

d

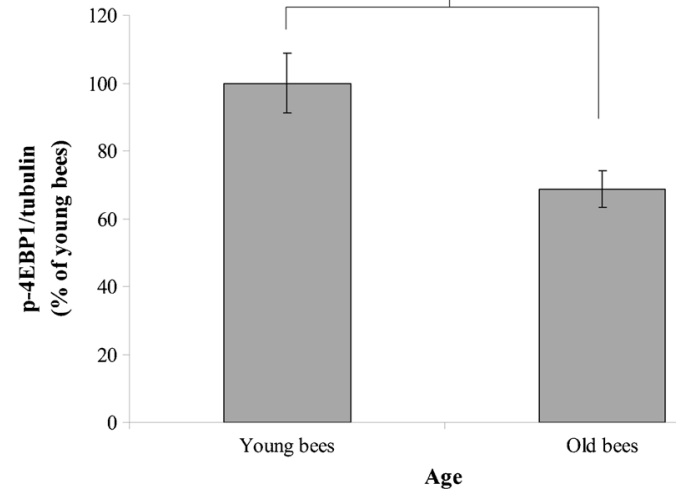

Figure 5. eIF4E expression and p-4EBP1 levels in the trophocytes and oenocytes of young and old worker bees. eIF4E (a) and p-4EBP1 (c) were analyzed by Western blotting. Tubulin served as a loading control. $Y$ young worker bees, $O$ old worker bees, $P$ positive control (mice liver). eIF4E (b ) and p-4EBP1 (d) were normalized to the expression in young worker bees; the results are shown as percentages and represent the mean $\pm \operatorname{SEM}(n=10)$. The asterisks indicate significant differences $\left({ }^{*} P<0.05,{ }^{*} P<0.01\right.$; two-sample $t$ test).

$\beta$-oxidation increase the $\Delta \psi \mathrm{m}$ and generate a high ATP concentration, concomitant with high $\mathrm{NAD}^{+}$, ROS concentrations, and SOD activity.

Activated adenosine monophosphateactivated protein kinase (AMPK) promotes lipolysis (Yin et al. 2003), $\beta$-oxidation (Lee et al. 2006), and ATP production (Cantó et al. 2009). Silent information regulator 1 (SirT1) also activates $\beta$-oxidation (Purushotham et al. 2009). Further, increased NEFA concentration via lipase stimulates $\beta$-oxidation (Yang and $\mathrm{Li}$ 2007). Parallel decreases in $\beta$-oxidation, NEFA concentration, AMPK activity (Hsu and Chuang 2014), SirT1 activity (Hsu and Chuang 2014), and ATP concentration (Chuang and Hsu 2013; Hsu and Chan 2013;
Hsu and Chuang 2014) with age indicate that AMPK and SirT1 may activate lipase activity, thereby increasing the concentration of NEFAs for $\beta$-oxidation in young worker bees. These results are consistent with previous studies showing that hibernating mammals increase fat metabolism by increasing NEFA concentration (Andrews 2004).

\subsection{FAS activity and fat accumulation}

In this study, FAS activity increased with age in the trophocytes and oenocytes of worker bees, indicating that lipogenesis increased with age. This observation is consistent with previous studies showing that aging is 
associated with a shift of fatty acid metabolism toward lipogenesis (Kuhla et al. 2011) and that fat accumulation increases with age in mice (Houtkooper et al. 2011) and rats (Carlile and Lacko 1985). Parallel increases in fat accumulation, protein oxidation, and lipid peroxidation (Hsieh and Hsu 2011) with age indicate that fat accumulation is correlated with oxidative stress in trophocytes and oenocytes. These results are supported by previous studies showing that fat accumulation is correlated with oxidative stress in humans and mice (Furukawa et al. 2004).

Activated AMPK inhibits FAS activity and fatty acid synthesis in rat (Sullivan et al. 1994). In addition, SirT1 inhibits FAS expression, increases lipolysis, and decreases fat synthesis (Picard et al. 2004). In this study, FAS activity and fat accumulation were inversely proportional to AMPK and SirT1 activities (Hsu and Chuang 2014), suggesting that AMPK and SirT1 inhibit FAS activity in young worker bees, which resulted in a low level of fat accumulation.

\subsection{Glucose utilization}

PFKFB3 synthesizes fructose-2,6bisphosphate, which is the most potent stimulator of glycolysis (Yalcin et al. 2009). PFKFB3 overexpression results in increased glycolysis (Atsumi et al. 2005). Further, PK catalyzes the rate-limiting step in glycolysis. In this study, PFKFB3 expression, $\mathrm{PK}$ activity, and the $\mathrm{PDH} / \mathrm{CS}$ ratio did not significantly differ, indicating that glycolysis was similar between the trophocytes and oenocytes of young and old worker bees. Previous studies demonstrated that glycolysis decreases with age in the skeletal muscles of mice and in yeast (Lee et al. 1999; Lin et al. 2001). The most likely reason for these discrepant findings is that honey is the major energy source for worker bees, causing a lack of a significant difference in glycolysis between young and old worker bees.

\subsection{Lactate concentrations}

Glycolysis did not significantly differ in the trophocytes and oenocytes of young and old worker bees. However, the trophocytes and oenocytes of old worker bees exhibited reduced mitochondrial energy utilization (Chuang and Hsu 2013). These results suggest that the trophocytes and oenocytes of old worker bees may undergo anaerobic metabolism ( $\mathrm{Ji}$ et al. 2016). Lactate is produced from pyruvate via lactate dehydrogenase in anaerobic metabolism. In this study, lactate concentrations in trophocytes and oenocytes were similar between young and old worker bees, indicating that old worker bees did not have increased anaerobic metabolism. Most energy derived from glycolysis is likely used to synthesize lipids or glycogen in old worker bees. This inference is consistent with this study showing that fat and glycogen accumulation increased with age and previous studies showing that aging results in a shift in cellular metabolism to lipogenesis (Kuhla et al. 2011) and energy storage (Lin et al. 2001).

\subsection{Glycogen accumulation}

p-GSK3, an inactive form of GSK3, is produced by protein kinase B (Cross et al. 1995), cyclic adenosine monophosphate (cAMP)-dependent protein kinase A (Fang et al. 2000), or ribosomal protein S6 kinase (Sutherland and Cohen 1994). p-GSK3 cannot inhibit glycogen synthase activity, which results in an increase in glycogen synthesis. In this study, the decrease in p-GSK3 level with age indicated that the trophocytes and oenocytes of young worker bees have increased glycogen synthesis compared with old worker bees. This finding is consistent with previous studies showing that glycogen synthase activity decreases with age in rat skeletal muscles (Dall'Aqlio et al. 1987) and liver (Khandelwal et al. 1984) and that $\mathrm{p}-\mathrm{GSK} 3 \beta$ level decreases with age in rat brain, extensor digitorum longus, and soleus (Solas et al. 2010; Kinnard et al. 2005).

Parallel decreases in p-GSK3 and cAMP concentrations (Hsu and Chuang 2014) with age indicate that cAMP may activate cAMPdependent protein kinase A to phosphorylate GSK3 in the trophocytes and oenocytes of young worker bees. AMPK inhibits glycogen 
synthesis (Hardie 2011). The increases in glycogen accumulation and glycogen concentration and the decrease in AMPK activity (Hsu and Chuang 2014) with age suggest that AMPK inhibits glycogen synthesis in the trophocytes and oenocytes of young worker bees and glycogen inhibits AMPK activity in the trophocytes and oenocytes of old worker bees. This inference is supported by a previous study, showing that AMPK $\beta$ subunits contain a glycogen-binding domain and glycogen inhibits AMPK activity (McBride et al. 2009).

Aging increases energy storage, one hallmark of which is glycogen accumulation (Lin et al. 2001). The increase in glycogen accumulation and glycogen concentration with age in the trophocytes and oenocytes of worker bees in this study is consistent with previous studies showing that glycogen accumulation increases with age in many somatic tissues and cells in different animal models (Lin et al. 2001; Seo et al. 2008; Sinadinos et al. 2014).

\subsection{Protein synthesis}

eIF4E is a key mRNA translation initiation factor that determines the rate of cap-dependent protein synthesis (Gingras et al. 1999). A deletion mutant of eIF4E/ife-2 gene, ife-2(ok306), causes decreased protein synthesis in Caenorhabditis elegans (Syntichaki et al. 2007). The dissociation of $\mathrm{p}$-4EBP1 from eIF4E results in the initiation of translation (Clemens 2001). In this study, eIF4E expression and p-4EBP1 level decreased with age in the trophocytes and oenocytes of worker bees, representing that protein synthesis declines with age. These results are consistent with previous studies in diverse species (Rattan and Clark 1996; Hudson et al. 1998). Notably, a previous study has demonstrated that $30-40 \%$ of total ATP is used in protein synthesis (Buttgereit and Brand 1995). Parallel decreases in eIF4E expression, p-4EBP1 level, $\beta$-oxidation, and ATP concentration (Hsu and Chuang 2014; Hsu and Chan 2013; Chuang and Hsu 2013) with age in bees suggest that $\beta$ oxidation may provide the energy for protein synthesis in young worker bees. This inference is supported by a previous study showing that $\beta$ - oxidation of fatty acids is required to regulate protein synthesis in rat hearts (Crozier et al. 2002).

\section{ACKNOWLEDGMENTS}

This work was supported by grants (CMRPD1E0021, CMRPD 1 E 0381 , CMRPD 1 E 0022 , and CMRPD1G0081) from the Chang Gung Memorial Hospital, Linkou, Taiwan.

\section{CONTRIBUTIONS}

$\mathrm{C}-\mathrm{YH}$ conceived this research and designed experiments; C-YL and Y-LC performed experiments and analysis; C-YH wrote the paper and participated in the revisions of it.

\section{COMPLIANCE WITH ETHICAL STANDARDS}

Conflict of interest The authors declare that they have no conflict of interest.

Experimental ethics statement All institutional and national guidelines for the care and use of laboratory animals were followed.

Le vieillissement entraîne une diminution du métabolisme énergétique cellulaire dans les trophocytes et les oenocytes des ouvrières d'abeilles (Apis mellifera)

Métabolisme cellulaire / Apidae / ouvrière âgée / baisse du métabolisme

Das Altern resultiert in einer Verringerung des zellulären Energiestoffwechsels in Trophozyten und Oenozyten von Arbeiterinnen der Honigbiene (Apis mellifera)

Alterungsprozess / zellulärer Energiestoffwechsel / Trophozyten / Oenozyten / Honigbiene

\section{REFERENCES}

Andrews, M.T. (2004) Genes controlling the metabolic switch in hibernating mammals. Biochem. Soc. Trans. 32, 1021-1024

Atsumi, T., Nishio, T., Niwa, H., Takeuchi, J., Bando, H., Shimizu, C., Yoshioka, N., Bucala, R., Koike, T. (2005) Expression of inducible 6-phosphofructo-2- 
kinase/fructose-2,6-bisphosphatase/PFKFB3 isoforms in adipocytes and their potential role in glycolytic regulation. Diabetes 54, 3349-3357

Bey, L., Areiqat, E., Sano, A., Hamilton, M.T. (2001) Reduced lipoprotein lipase activity in postural skeletal muscle during aging. J. Appl. Physiol. 91, 687-692

Brown, J.P., Perham, R.N. (1976) Selective inactivation of the transacylase components of the 2-oxo acid dehydrogenase multienzyme complexes of Escherichia coli . Biochem. J. 155 , 419-427

Buttgereit, F., Brand, M.D. (1995) A hierarchy of ATPconsuming processes in mammalian cells. Biochem. J. 312, 163-167

Calles-Escandon, J., Arciero, P.J., Gardner, A.W., Bauman, C., Poehlman, E.T. (1995) Basal fat oxidation decreases with aging in women. J. Appl. Physiol. 78, 266-271

Cantó, C., Gerhart-Hines, Z., Feige, J.N., Lagouge, M., Noriega, L., Milne, J.C., Elliott, P.J., Puigserver, P., Auwerx, J. (2009) AMPK regulates energy expenditure by modulating $\mathrm{NAD}^{+}$metabolism and SIRT1 activity. Nature 458, 1056-1060

Carlile, S.I., Lacko, A.G. (1985) Age-related changes in plasma lipid levels and tissue lipoprotein lipase activities of Fischer-344 rats. Arch. Gerontol. Geriatr. 4, $133-140$

Chan, Q.W.T., Mutti, N.S., Foster, L.J., Kocher, S.D., Amdam, G.V., Florian, W. (2011) The worker honeybee fat body proteome is extensively remodeled preceding a major life-history transition. PLoS ONE 6, e24794

Chuang, Y.L., Hsu, C.Y. (2013) Changes in mitochondrial energy utilization in young and old worker honeybees (Apis mellifera). Age 35, 1867-1879

Clemens, M.J. (2001) Translational regulation in cell stress and apoptosis. Roles of the eIF4E binding proteins. J. Cell Mol. Med. 5, 221-239

Cordiner, S., Egginton, S. (1997) Effects of seasonal temperature acclimatization on muscle metabolism in rainbow trout, Oncorhynchus mykiss. Fish Physiol. Biochem. 16, 333-343

Cross, D.A.E., Alessi, D.R., Cohen, P., Andjelkovich, M., Hemmings, B.A. (1995) Inhibition of glycogen synthase kinase- 3 by insulin mediated by protein kinase $\mathrm{B}$. Nature 378, 785-788

Crozier, S.J., Bolster, D.R., Reiter, A.K., Kimball, S.R., Jefferson, L.S. (2002) Beta-oxidation of free fatty acids is required to maintain translational control of protein synthesis in heart. Am. J. Physiol. Endocrinol. Metab. 283, E1144-E1150

Dall'Aqlio, E., Chang, H., Reaven, G.M., Azhar, S. (1987) Age-related changes in rat muscle glycogen synthase activity. J. Gerontol. 42 , 168-172

Desrosiers, V., Le François, N.R., Tveiten, H., Andreassen, I., Blier, P.U. (2008) Ontogenesis of catabolic and energy metabolism capacities during the embryonic development of spotted wolfish (Anarhichas minor). Comp. Biochem. Physiol. B Biochem. Mol. Biol. 150, 200-206
Elsik, C.G., Worley, K.C., Bennett, A.K., Beye, M., Camara, F., et al. (2014) Finding the missing honey bee genes: lessons learned from a genome upgrade. BMC Genomics 15, 86

Fang, X., Yu, S.X., Lu, Y., Bast, R.C., Woodgett, J.R., Mills, G.B. (2000) Phosphorylation and inactivation of glycogen synthase kinase 3 by protein kinase A. Proc. Natl. Acad. Sci. USA 97, 11960-11965

Furukawa, S., Fujita, T., Shimabukuro, M., Iwaki, M., Yamada, Y., Nakajima, Y., Nakayama, O., Makishima, M., Matsuda, M., Shimomura, I. (2004) Increased oxidative stress in obesity and its impact on metabolic syndrome. J. Clin. Invest. 114, 1752-1761

Gingras, A.C., Raught, B., Sonenberg, N. (1999) eIF4 initiation factors: effectors of mRNA recruitment to ribosomes and regulators of translation. Annu. Rev. Biochem. 68, 913-963

Hardie, D.G. (2011) AMP-activated protein kinase - an energy sensor that regulates all aspects of cell function. Genes Dev. 25, 1895-1908

Houtkooper, R.H., Argmann, C., Houten, S.M., Cantó, C., Jeninga, E.H., Andreux, P.A., Thomas, C., Doenlen, R., Schoonjans, K., Auwerx, J. (2011) The metabolic footprint of aging in mice. Sci. Rep. 1, 134

Hsieh, Y.S., Hsu, C.Y. (2011) Honeybee trophocytes and fat cells as target cells for cellular senescence studies. Exp. Gerontol. 46, 233-240

Hsu, C.Y., Chan, Y.P. (2013) The use of honeybees reared in a thermostatic chamber for aging studies. Age 35, $149-158$

Hsu, C.Y., Chuang, Y.L. (2014) Changes in energyregulated molecules in the trophocytes and fat cells of young and old worker honeybees (Apis mellifera). J. Gerontol. A Biol. Sci. Med. Sci. 69, 955-964

Hsu, C.Y., Hsieh, Y.S. (2014) Oxidative stress decreases in the trophocytes and fat cells of worker honeybees during aging. Biogerontology 15, 129-137

Hsu, C.Y., Chuang, Y.L., Chan, Y.P. (2014) Changes in cellular degradation activity in young and old worker honeybees (Apis mellifera ). Exp. Gerontol. 50, 128-136

Hudson, E.K., Tsuchiya, N., Hansford, R.G. (1998) Ageassociated changes in mitochondrial mRNA expression and translation in the Wistar rat heart. Mech. Ageing Dev. 103, 179-193

Ji, X., Ku, T., Zhu, N., Ning, X., Wei, W., Li, G., Sang, N. (2016) Potential hepatic toxicity of buprofezin at sublethal concentrations: ROS-mediated conversion of energy metabolism. J. Hazard. Mater. 320, 176-186

Karlic, H., Lohninger, S., Koeck, T., Lohninger, A. (2002) Dietary L-carnitine stimulates carnitine acyltransferases in the liver of aged rats. J. Histochem. Cytochem. 50, 205-212

Khandelwal, R.L., Enno, T.L., Narayanan, N. (1984) Effects of age on glycogen synthase and phosphorylase activities in rat liver. Mech. Ageing Dev. 28, 13-22

Kinnard, R.S., Mylabathula, D.B., Uddemarri, S., Rice, K.M., Wright, G.L., Blough, E.R. (2005) Regulation 
of p70S6K, GSK-3B, and calcineurin in rat striated muscle during aging. Biogerontology 6, 173-184

Kostyak, J.C., Kris-Etherton, P., Bagshaw, D., DeLany, J.P., Farrell, P.A. (2007) Relative fat oxidation is higher in children than adults. Nutr. J. 6, 19

Kuhla, A., Blei, T., Jaster, R., Vollmar, B. (2011) Aging is associated with a shift of fatty metabolism toward lipogenesis. J. Gerontol. A Biol. Sci. Med. Sci. 66, 1192-1200

Lee, CK, Klopp, R.G., Weindruch, R., Prolla, T.A. (1999) Gene expression profile of aging and its retardation by caloric restriction. Science 285, 1390-1393

Lee, W.J., Kim, M., Park, H.S., Kim, H.S., Jeon, M.J., et al. (2006) AMPK activation increases fatty acid oxidation in skeletal muscle by activating PPARalpha and PGC1. Biochem. Biophys. Res. Commun. 340, 291-295

Levadoux, E., Morio, B., Montaurier, C., Puissant, V., Boirie, Y., Fellmann, N., Picard, B., Rousset, P., Beaufrere, B., Ritz, P. (2001) Reduced whole-body fat oxidation in women and in the elderly. Int. J. Obes. Relat. Metab. Disord. 25, 39-44

Lin, S.S., Manchester, J.K., Gordon, J.I. (2001) Enhanced gluconeogenesis and increased energy storage as hallmarks of aging in Saccharomyces cerevisiae. J. Biol. Chem. 276, 36000-36007

McBride, A., Ghilagaber, S., Nikolaev, A., Hardie, D.G. (2009) The glycogen-binding domain on the AMPK beta subunit allows the kinase to act as a glycogen sensor. Cell Metab. 9, 23-34

Nepokroeff, C.M., Lakshmanan, M.R., Porter, J.W. (1975) Fatty acid synthase from rat liver. Methods Enzymol. 35, 37-44

Nicholls, D.G. (2004) Mitochondrial membrane potential and aging. Aging Cell 3, 35-40

Picard, F., Kurtev, M., Chung, N., Topark-Nqarm, A., Senawong, T., Machado De Oliveira, R., Leid, M., McBurney, M.W., Guarente, L. (2004) Sirt1 promotes fat mobilization in white adipocytes by repressing PPAR-gamma. Nature 429, 771-776

Purushotham, A., Schug, T.T., Xu, Q., Surapureddi, S., Guo, X., Li, X. (2009) Hepatocyte-specific deletion of SIRT1 alters fatty acid metabolism and results in hepatic steatosis and inflammation. Cell Metab. 9, 327-338

Rattan, S.I., Clark, B.F. (1996) Intracellular protein synthesis, modifications and aging. Biochem. Soc. Trans. 24, 1043-1049

Seehuus, S.C., Taylor, S., Petersen, K., Aamodt, R.M. (2013) Somatic maintenance resources in the honeybee worker fat body are distributed to withstand the most life-threatening challenges at each life stage. PLoS ONE 8, e69870
Seo, Y.H., Jung, H.J., Shin, H.T., Kim, Y.M., Yim, H., Chung, H.Y., Lim, I.K., Yoon, G. (2008) Enhanced glycogenesis is involved in cellular senescence via GSK3/GS modulation. Aging Cell 7, 894-907

Sinadinos, C., Valles-Ortega, J., Boulan, L., Solsona, E., Tevy, M.F., Marquez, M., Duran, J., Lopez-Iglesias, C., Calbó, J., Blasco, E., et al. (2014) Neuronal glycogen synthesis contributes to physiological aging. Aging Cell 13, 935-945

Solas, M., Aisa, B., Mugueta, M.C., Rỉo, J.D., Tordera, R.M., Ramirez, M.J. (2010) Interactions between age, stress and insulin on cognition: implications for Alzheimer's disease. Neuropsychopharmacology 35, 1664-1673

Son, N., Hur, H.J., Sung, M.J., Kim, M.S., Hwang, J.T., et al. (2012) Liquid chromatography-mass spectrometry-based metabolomic analysis of liver from aged rats. J. Proteome Res. 11, 2551-2558

Sullivan, J.E., Brocklehurst, K.J., Marley, A.E., Carey, F., Carling, D., Beri, R.K. (1994) Inhibition of lipolysis and lipogenesis in isolated rat adipocytes with AICAR, a cell-permeable activator of AMP-activated protein kinase. FEBS Lett. 353, 33-36

Sutherland, C., Cohen, P. (1994) The $\alpha$-isoform of glycogen synthase kinase- 3 from rabbit skeletal muscle is inactivated by $\mathrm{p} 70 \mathrm{~S} 6$ kinase or MAP kinase-activated protein kinase-1 in vitro. FEBS Lett. 338, 37-42

Syntichaki, P., Troulinaki, K., Tavernarkis, N. (2007) eIF4E function in somatic cells modulates ageing in Caenorhabditis elegans . Nature 445, 922-926

The honeybee genome sequencing consortium. (2006) Insights into social insects from the genome of the honeybee Apis mellifera. Nature 443, 931-949

Tucker, M.Z., Turcotte, L.P. (2002) Impaired fatty acid oxidation in muscle of aging rats perfused under basal conditions. Am. J. Physiol. Endocrinol. Metab. 282, E1102-E1109

Valentine, B.A., Cooper, B.J. (2006) Development of polyglucosan inclusions in skeletal muscle. Neuromuscul. Disord. 16, 603-607

Yalcin, A., Telang, S., Clem, B., Chesney, J. (2009) Regulation of glucose metabolism by 6-phosphofructo-2kinase/fructose-2,6-bisphosphatases in cancer. Exp. Mol. Pathol. 86, 174-179

Yang, Q., Li, Y. (2007) Roles of PPARs on regulating myocardial energy and lipid homeostasis. J. Mol. Med. 85, 697-706

Yin, W., Mu, J., Birnbaum, M.J. (2003) Role of AMPactivated protein kinase in cyclic AMP-dependent lipolysis in 3T3-L1 adipocytes. J. Biol. Chem. 278, 43074-43080 